\title{
RELAÇÃO ENTRE CARACTERÍSTICAS BIOQUÍMICAS E AGRONÔMICAS E O ENFEZAMENTO PÁLIDO EM MILHO ${ }^{1}$
}

\author{
ISABEL REGINA PRAZERES DE SOUZA ${ }^{2}$, ELIZABETH DE OLIVEIRA ${ }^{2}$, CHARLES MARTINS \\ DE OLIVEIRA ${ }^{3}$, HÉLIO TEIXEIRA PRATES ${ }^{2}$, RONALDO RODRIGUES COIMBRA ${ }^{4}$, MARCUS \\ JOSÉ CONCEIÇÃO LOPES ${ }^{5}$
}

\author{
${ }^{1}$ Trabalho parcialmente financiado pela Fapemig, Processo 885/97 e Prodetab 162-01/98 \\ ${ }^{2}$ Pesquisadores, Embrapa Milho e Sorgo. Caixa Postal 151, CEP. 35701-970 Sete Lagoas, MG, E-mail: \\ isabel@cnpms.embrapa.br (autor para correspondência). \\ ${ }^{3}$ Bolsista Recém-Doutor CNPq. \\ ${ }^{4}$ Bolsista Doutorando Fapemig. \\ ${ }^{5}$ Bolsista Convênio Embrapa/Unicentro Isabella Hendrix.
}

Revista Brasileira de Milho e Sorgo, v.2, n.1, p.9-19, 2003

\begin{abstract}
RESUMO - Foram avaliadas, em plântulas de milho, características bioquímicas, como possíveis marcadores para seleção de genótipos resistentes ao enfezamento pálido, causado por Spiroplasma kunkelii, bem como o efeito dessa doença sobre o crescimento e a produção de genótipos de milho. Para isto, espiroplasma foi inoculado nas plântulas das linhagens parentais susceptível, $\mathrm{P} 1$, e resistente, $\mathrm{P} 2$, e nas gerações $\mathrm{F}_{1}, \mathrm{~F}_{2}$ e $\mathrm{F}_{3}$. Essas linhagens parentais, utilizadas também em intercruzamentos para obtenção das demais gerações, são oriundas do programa de melhoramento da Embrapa Milho e Sorgo. A altura das plantas (AP), a altura de espiga (AE) e a produção de grãos (PG) foram as características afetadas pela infecção por espiroplasma, que causou reduções médias de, respectivamente, $9,60 \%, 12,83 \%$ e $42 \%$ nesses parâmetros. Elevados valores, acima de 0,80 , foram obtidos em correlações fenotípica e genotípica entre nota da espiga (NE) e severidade da doença enfezamento pálido (SEV), entre SEV e PG e entre NE e PG, mostrando que essas características podem ser utilizadas como critério para seleção de genótipos resistentes ao enfezamento pálido. Dentre as características bioquímicas avaliadas, verificou-se tendência de as plantas resistentes apresentarem maiores valores de teor de proteínas solúveis e menores valores de atividade específica da peroxidase (PODesp). As correlações fenotípicas entre os teores de ácidos ferúlico (FA) e 5,5'-di-ferúlico (DFA) e SEV não foram significativas e os zimogramas da peroxidase não apresentaram isoformas que estivessem associadas especificamente à resistência ou à susceptibilidade ao enfezamento pálido.
\end{abstract}

Palavras-chave: Zea mays; peroxidase; ácidos ferúlico e 5,5'-di-ferúlico; espiroplasma; Spiroplasma kunkelii.

\section{RELATIONSHIP BETWEEN BIOCHEMICALAND AGRONOMICAL CHARACTERISTICS AND THE CORN STUNT IN MAIZE}

\begin{abstract}
Biochemical characteristics were evaluated in maize seedlings, as possible markers for selection of resistant genotypes to the corn stunt disease caused by Spiroplasma kunkelii, as well as the effect of this disease over the growth and grain production of maize genotypes. Spiroplasma was inoculated in the seedlings of the parental inbred lines P1, susceptible, and $\mathrm{P} 2$, resistant, and of the generations $\mathrm{F}_{1}, \mathrm{~F}_{2}$ and $\mathrm{F}_{3}$. These inbred lines, also
\end{abstract}


used in the intercrosses to obtain the other generations, were from the breeding program of the Brazilian Maize and Sorghum Corporation. The Plant Height (AP), ear height (AE) and grain production $(\mathrm{PG})$ were affected by the spiroplasma with mean reductions of, respectively, $9.60 \%$, $12.83 \%$ and $42.00 \%$ in these parameters. High values, above 0,80 were obtained in phenotypic and genotypic correlation between ear grade (NE) $x$ corn stunt disease severity (SEV), between SEV x PG and between NE x PG, showing that these characteristics can be used as criteria for the selection of resistant genotypes to corn stunt. Among the biochemical characteristics evaluated, a tendency of the resistant plants to show higher values for soluble protein content and lower values for peroxidase specific activity (PODesp) was observed. The phenotypic correlation among the ferulic (FA) and 5,5'-di-ferulic (DFA) acids and SEV was not significant and the peroxidase zimograms did not present any isoforms that were associated specifically with resistance or susceptibility to corn stunt.

Key words: Zea mays; peroxidase; ferulic and 5,5'-di-ferulic acids; spiroplasma; Spiroplasma kunkelii.

Em milho, o enfezamento pálido, causado por Spiroplasma kunkelii, foi registrado pela primeira vez no Brasil em 1970 (Kitajima \& Costa, 1970), mas somente a partir da década de 80 essa doença passou a causar perdas significativas na cultura, em diversas regiões do país (Bedendo, 1999). Atualmente, perdas da ordem de $100 \%$ têm sido registradas em plantios no Brasil Central (Oliveira et al., 1998). O espiroplasma é transmitido de forma persistente e propagativa por várias espécies de cigarrinhas, principalmente por Dalbulus maidis, que é a única espécie vetora encontrada no Brasil (Nault, 1980; Oliveira, 1996).

O uso de cultivares de milho resistentes ao enfezamento pálido é a alternativa mais eficiente para seu controle. Contudo, a seleção de genótipos de milho com base nos sintomas foliares, em campo, constitui processo relativamente demorado e laborioso. Em geral, os sintomas do enfezamento pálido manifestam-se durante o período de enchimento dos grãos de milho (Oliveira et al., 2002) e, por isso, há necessidade de esperar a planta completar seu ciclo para tais avaliações. $\mathrm{O}$ desenvolvimento de métodos alternativos, para pronta identificação da resistência genética do milho ao espiroplasma, pode permitir a aceleração no processo de seleção dos materiais, representando ganho significativo na obtenção de cultivares resistentes ao enfezamento pálido.

Por outro lado, a elucidação dos mecanismos bioquímicos envolvidos na resistência do milho ao espiroplasma também pode contribuir para o desenvolvimento de novos métodos de seleção e/ ou de controle do enfezamento pálido.

Entre outros compostos bioquímicos, os ácidos ferúlico e diferúlico e a enzima peroxidase têm sido freqüentemente relacionados aos mecanismos de resistência a doenças de diferentes espécies vegetais e uma possível relação entre plântulas não infectadas e sua resistência a patógenos tem sido relatada em diversas interações patógeno-hospedeiro (Shimoni et al., 1996; Reuveni et al., 1992). Dentro desse contexto, a relação entre vários parâmetros bioquímicos e a resistência a doenças tem sido utilizada como critério de seleção de materiais de germoplasma e de melhoramento em diferentes culturas (Singh et al., 1990; Reuveni et al., 1992; BarZur, 1998). A importância de alguns desses fatores, tais como fenólicos e suas enzimas relacionadas, em conferir reação de resistência ou susceptibilidade tem sido demonstrada. Em plântulas de quiabo não-inoculado, Ahmed et al. (1992) encontraram teores 
mais elevados de fenólicos e de proteínas totais e solúveis nas variedades resistentes ao mosaico da nervura amarela. Entretanto, para a atividade da enzima peroxidase, não houve diferença significativa entre resistentes e susceptíveis. Singh et al.(1990) verificaram, em plântulas não-inoculadas de Cyamopsis tetragonoloba, altas correlações negativas entre fenólicos totais e atividade da peroxidase e resistência à mancha bacteriana. Em milho, Shimoni et al. (1996) demonstraram que específicas isoenzimas da peroxidase e B-1,3-glucanases foram correlacionadas com resistência ao E. turcicum.

Os objetivos deste trabalho foram avaliar a utilização de características bioquímicas: atividade e zimogramas da peroxidase, teor protéico e de ácidos ferúlico e 5,5'-di-ferúlico no estádio de plântula, como possíveis marcadores na seleção de genótipos de milho resistentes ao enfezamento pálido e avaliar o efeito dessa doença sobre as características agronômicas, desenvolvimento e produção de plantas de milho.

\section{Material e Métodos}

\section{1- Material vegetal}

Foram utilizadas linhagens parentais $\mathrm{P} 1 \mathrm{e} \mathrm{P} 2$ (tratamentos 1 e 2, respectivamente, susceptível e resistente ao enfezamento pálido), híbrido $\mathrm{F}_{1}$ (tratamento 3), indivíduos $\mathrm{F}_{2}$ (tratamento 4) e 30 famílias $\mathrm{F}_{3}$ (tratamentos 5 a 34). Essas linhagens parentais, utilizadas na obtenção das demais gerações, são oriundas do programa de melhoramento da Embrapa Milho e Sorgo.

\section{2-Delineamento Experimental}

Para as características AP, AE e PG, considerou-se o delineamento de blocos ao acaso em arranjo de parcelas subdivididas com três repetições. As parcelas foram constituídas pelos genótipos e as subparcelas, pelos níveis de inoculação (inoculados e não-inoculados). Cada tratamento correspondia a uma parcela constituída por uma fileira de $4 \mathrm{~m}$ de comprimento, espaçadas de $0,90 \mathrm{~m}$, com densidade de semeadura de cinco sementes por metro linear.

Para as características, POD, PODesp e PROT, empregou-se o delineamento experimental de blocos ao acaso com três repetições, sendo considerados os 34 genótipos. Entretanto, para as características FA1, DFA1, DFA/FA, FA2 e DFA2, devido à complexidade e custo das análises laboratoriais, foram consideradas 20 famílias F3 ao invés de 30 , totalizando 24 genótipos, mantendo-se o delineamento de blocos ao acaso, entretanto, com duas repetições.

Para o estudo de correlações entre características, considerou-se o delineamento em blocos ao acaso. Para as características AP, AE e PG, foram consideradas apenas as subparcelas submetidas à inoculação.

\section{3- Inoculação}

Foram inoculadas cinco plântulas por parcela; estas germinaram sob gaiolas constituídas de garrafas de plástico transparentes, de refrigerante de dois litros, que continham aberturas laterais protegidas por tecido voil, para ventilação (Oliveira et al., 2002a) e fixadas ao solo por um suporte metálico e etiquetadas, individualmente. Cigarrinhas infectivas com espiroplasma foram obtidas através da metodologia descrita por Nault (1980), sendo utilizado para transporte até o campo o acondicionamento de três cigarrinhas em tubos transparentes de caneta esferográfica. Essas cigarrinhas foram transferidas para o interior de cada uma das gaiolas utilizando-se aspirador bucal e permaneceram alimentando-se das plântulas por aproximadamente quatro dias, para a inoculação do espiroplasma. A partir daí, as plântulas inoculadas tiveram a gaiola retirada e foram pulverizadas imediatamente e semanalmente até o enchimento de grãos, utilizandose o inseticida sistêmico imidacloprid (Bayer SA), na dose de $150 \mathrm{~g} \mathrm{ha}^{-1}$, para evitar uma possível 
contaminação das plantas em estudo, por patógenos transmitidos por cigarrinhas do campo. As plântulas restantes na parcela e não inoculadas foram também pulverizadas semanalmente com o mesmo sistêmico, desde a germinação até a fase de enchimento de grãos.

\section{4- Características avaliadas}

Imediatamente antes da inoculação:

Imediatamente antes da inoculação, aos 10 dias após o plantio, as cinco plântulas na parcela, já protegidas por gaiola, tiveram as $3^{\mathrm{a}}$ e $4^{\mathrm{a}}$ folhas coletadas para análises das características: teor de ácidos ferúlico (FA) e 5,5'-di-ferúlico (DFA), com suas unidades expressas tanto em relação à parede celular (PC) (FA1 e DFA1 $\left(\mu \mathrm{g} \mathrm{mg}^{-1} \mathrm{PC}\right)$ ) quanto em relação ao peso fresco (PF) (FA2 e DFA2 $\left(\mu \mathrm{g} \mathrm{mg}^{-1}\right.$ $\mathrm{PF})$ ), a razão entre os ácidos 5,5'-di-ferúlico e ferúlico (DFA/FA), teor protéico (PROT $\left(\mathrm{mg} \mathrm{g}^{-1}\right.$ $\mathrm{PF})$ ), atividade da peroxidase (POD) expressa em relação ao peso fresco $\left(\mathrm{A}_{470} \mathrm{~min}^{-1} \mathrm{~g}^{-1} \mathrm{PF}\right)$ e atividade específica (PODesp) expressa em relação ao teor protéico $\left(\mathrm{A}_{470} \mathrm{~min}^{-1} \mathrm{mg}^{-1} \mathrm{PROT}\right)$.

Fase de florescimento masculino elou maturação fisiológica:

Foram avaliadas a produção de grãos (PG), que refere-se à média de produção de grãos/planta não-inoculada e inoculada, altura de planta (AP), medida em cm, do solo até a inserção da folha bandeira, e altura de espiga (AE), medida em cm, do solo até a inserção da primeira espiga, de cima para baixo.

Fase de enchimento dos grãos:

Realizaram-se duas avaliações da severidade de sintomas do enfezamento pálido (SEV), espaçadas de 15 dias e de acordo com a seguinte escala de notas: 0-ausência de sintomas; 1-presença de sintomas em pelo menos uma folha; 2-Aproximadamente $25 \%$ das folhas com sintomas; 3 - aproximadamente $50 \%$ das folhas com sintomas; 4 -acima de
50\% de folhas com sintomas, 5-planta inteira com sintomas ou início de morte precoce. Avaliou-se a primeira espiga (NE) das plantas inoculadas, por ocasião da avaliação para SEV, utilizando-se a escala de notas: $0=$ ausência de espiga; $1=$ espiga ruim, improdutiva e de menor tamanho na parcela; 2 = alguma produção e tamanho médio em relação à parcela e $3=$ produtiva e de melhor tamanho na parcela.

\section{5- Adubação e irrigação}

A adubação de plantio foi realizada de acordo com a análise química do solo, empregando-se a formulação N-P-K (5-20-20) e duas adubações nitrogenadas em cobertura, de $45 \mathrm{~kg} \mathrm{ha}^{-1}$ de $\mathrm{N}$, na forma de uréia, aos 30 e aos 45 dias após plantio. As irrigações foram suplementares, tendo como critério de manejo a evaporação da água do tanque classe A, conforme descrito por Albuquerque \& Andrade (2000), para reposição da lâmina de água.

\section{6- Deteç̧ão do patógeno nas plantas inocula- das apresentando sintomas de enfezamento}

A presença do espiroplasma foi detectada por teste de PCR ("Polymerase Chain Reaction") e microscopia eletrônica de transmissão (MET). Por ocasião do estádio de enchimento de grãos, coletou-se a folha bandeira de plantas inoculadas que apresentavam sintomas de enfezamento. A nervura central, retirada da porção basal dessas folhas, foi utilizada para os testes de PCR e MET, como descrito a seguir:

\section{1- Teste de PCR}

A extração de DNA genômico da nervura central foi realizada de acordo com o protocolo descrito por Saghai-Maroof et al. (1984). Realizou-se o teste de PCR multiplex, empregando-se, ao mesmo tempo, no desenvolvimento da reação, os pares de oligonucleotídeos específicos e universais para a identificação do espiroplasma e do fitoplasma, respectivamente, CSSF2 e CSSR6 (Barros et al., 2001) 
e R16F2 e R16R2 (Lee et al., 1995. Os fragmentos de PCR foram resolvidos em gel de agarose $0,8 \%$.

\section{2- Microscopia eletrônica de transmissão}

As amostras foram fixadas em tampão Milloning, contendo 2,5\% de glutaraldeído, pós-fixadas em tetróxido de ósmio $1 \%$, desidratadas em série alcool-acetona, incluídas em resina "Spurr", contrastadas com acetato de uranila e citrato de chumbo, após secção em ultramicrótomo e observadas ao microscópio eletrônico de transmissão, para verificar a presença de espiroplasma (Hayat, 1989).

\section{7- Atividade da peroxidase}

Análise da atividade da peroxidase foi realizada como descrito por Souza \& MacAdam (1998) a $30{ }^{\circ} \mathrm{C}$ em reação de mistura contendo tampão fosfato de potássio $96 \mathrm{mM} \mathrm{pH} \mathrm{6,0,} \mathrm{guaiacol} \mathrm{3,2}$ $\mathrm{mM}$ e peróxido de hidrogênio $0,38 \mathrm{mM}$. A reação foi iniciada pela adição de $10 \mu \mathrm{l}$ do extrato protéico e o aumento na absorbância min $^{-1}$ medido a $\mathrm{A}_{470}$ $\mathrm{nm}$.

\section{8- Análise protéica}

O teor de proteínas solúveis total foi determinado através do método de Bradford (1976), utilizando-se o protocolo de "microtiter plate" da BioRad (Hercules, CA, USA) para leitura em placa de ELISA, e absorbância lida a $595 \mathrm{~nm}$.

\section{9- Extração e quantificação dos ácidos ferúlico e diferúlico}

Extração de parede celular e liberação dos ácidos fenólicos de folhas de plântulas foram realizadas empregando-se a metodologia ajustada por Souza et al. (2002). A quantificação dos ácidos ferúlico e diferúlico foi realizada por meio de cromatógrafo líquido de alta eficiência (HPLC), marca Shimadzu, modelo LC-10 A, fase móvel, em gradiente linear de metanol (0-100\%) em tampão acetato de sódio 0,05 M, pH 4,0 (ajustado com ácido acético). Coluna fase reversa (C18), Hewlett Packard, com 4,6 mm x 250 mm, 5 mm de diâmetro de poro, fluxo de $1,0 \mathrm{ml} \mathrm{min}^{-1}$, volume injetado da amostra de $50 \mu 1$, comprimento de onda $(\lambda)$ igual a $300 \mathrm{~nm}$. Nessas condições, foi estabelecido o perfil cromatográfico dos ácidos ferúlico e 5,5'-di-ferúlico com os tempos de retenção $\left(\mathrm{t}_{\mathrm{R}}\right)$ de 17,1 min e 18,8 min, respectivamente (Prates et al., 2002).

\section{0- Análises estatísticas}

Análises de variância, coeficientes de correlação genotípica e fenotípica e o teste de média de Scott-Knott (1974) foram calculados utilizando-se o programa Genes (Cruz, 2001).

\section{Resultados e Discussão}

Detectou-se o espiroplasma tanto por microscopia eletrônica de transmissão (Figura $1 \mathrm{~A}$ e B) quanto pelo teste de PCR multiplex (Figura 2), em plantas inoculadas e que apresentavam sintomas de enfezamento. Essas detecções confirmaram a infecção das plantas apenas por espiroplasma.

Dentre as características agronômicas avaliadas, altura de planta (AP), altura de espiga (AE) e produção de grãos (PG), verificou-se significância a $1 \%$ de probabilidade pelo teste $\mathrm{F}$ para genótipos; entretanto, a interação genótipos e níveis de inoculação foi significativa somente para PG. Para as características AP e AE, o teste de Scott-knott demonstrou a separação dos tratamentos em cinco e três grupos, respectivamente (dados não mostrados). Verificou-se também que a inoculação reduziu em 9,6 \% a AP e em $12,83 \%$ a AE (Tabela 1 ). Redução em AP foi também verificada em híbridos comerciais, por Magalhães et al. (2001), que sugerem ser este um dos fatores a influenciar negativamente a disponibilização de fotoassimilados para o enchimento de grãos.

Para a característica PG, através do desdobramento de níveis de inoculação dentro de cada genótipo, verificou-se que os genótipos $2,4,8,9$, 

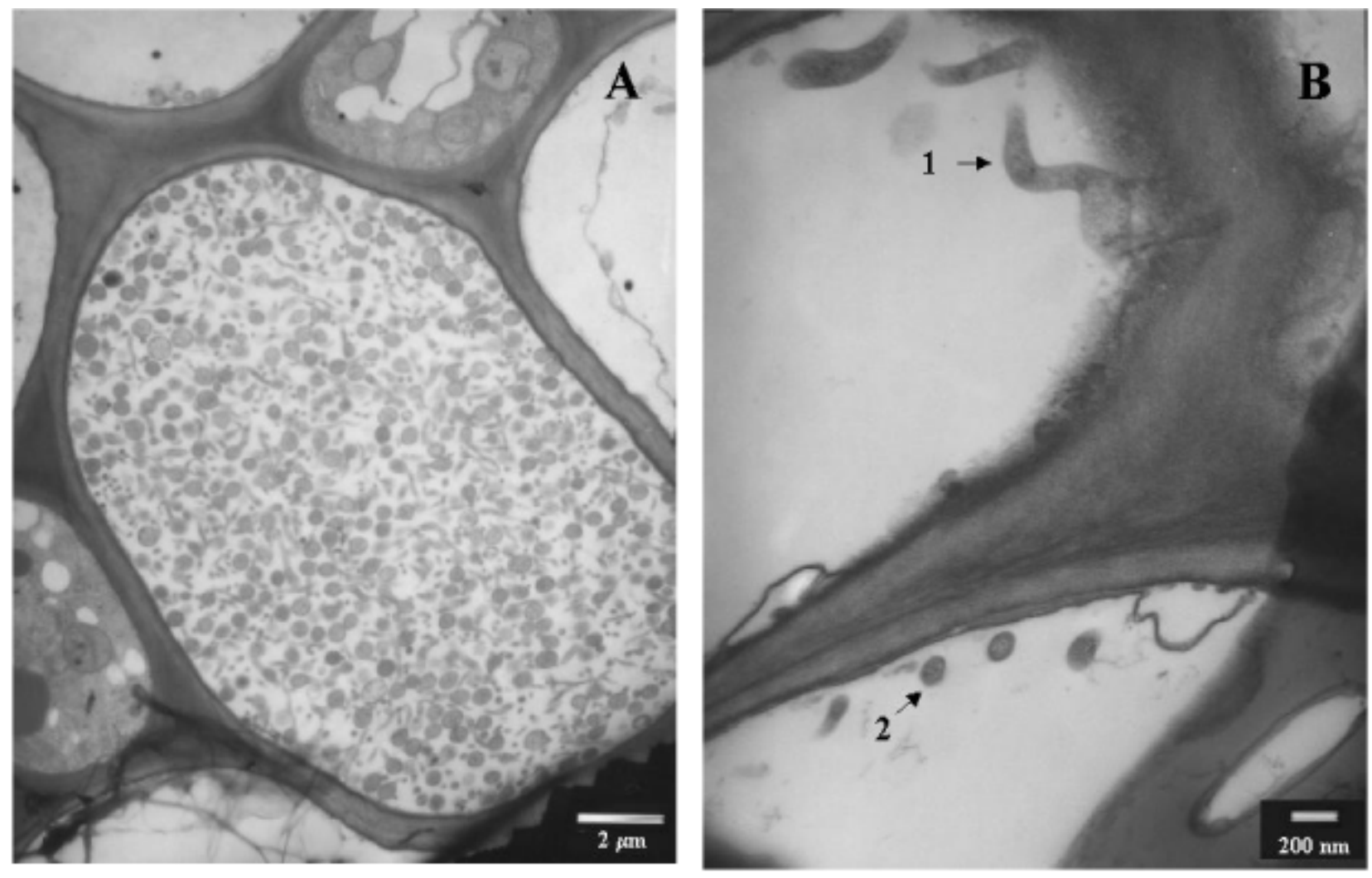

FIGURA 1. Fotos de microscopia eletrônica de transmissão, mostrando vaso do floema de folha de milho completamente preenchido com espiroplasma, em corte longitudinal (A) e transversal (B), indicados pelas setas 1 e 2 , respectivamente.

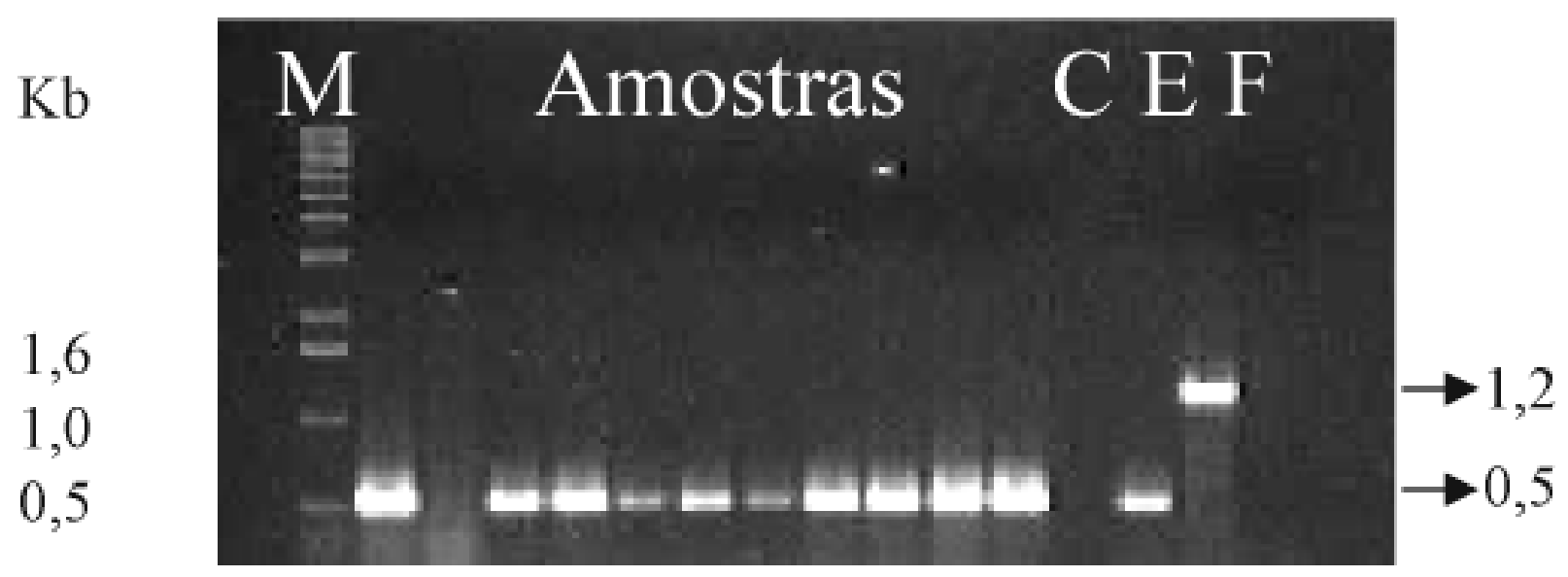

FIGURA 2. Resultado dos testes de PCR multiplex realizados em folhas de milho expressando sintomas de espiroplasma, por ocasião do enchimento de grãos. $\mathrm{M}=$ marcador de peso molecular, tamanho dos fragmentos em kilobase $(\mathrm{Kb}), \mathrm{C}=$ controle, sem DNA na reação de $\mathrm{PCR}, \mathrm{E}=$ controle para espiroplasma, fragmento de $0,5 \mathrm{~Kb}, \mathrm{~F}=$ controle para fitoplasma, fragmento de $1,2 \mathrm{~Kb}$. 
TABELA 1. Teste de Scott-Knott para as características altura de planta (AP) e altura de espiga (AE), considerando-se a média de todos os genótipos sob dois níveis de inoculação: inoculado e não-inoculado.

\begin{tabular}{ccc}
\hline \multirow{2}{*}{ Niveis de } & \multicolumn{2}{c}{ Características } \\
\cline { 2 - 3 } Inoculação & Altura de & Altura de \\
& Planta (cm) & Espiga (cm) \\
\hline Não-Inoculado & $148,24 \mathrm{a}$ & $61,66 \mathrm{a}$ \\
Inoculado & $133,99 \mathrm{~b}$ & $53,75 \mathrm{~b}$ \\
\hline Redução (\%) & 9,60 & 12,83 \\
\hline
\end{tabular}

Valores seguidos pela mesma letra, na coluna, não diferem significativamente a $5 \%$ de probabilidade.

$11,12,13,18,20,21,24,25,26,27,30,31$ e 33 não foram afetados pela inoculação (dados não mostrados). Dentre estes, observa-se, pelo gráfico de distribuição dos genótipos, para a característica produção de grãos, sob dois níveis de inoculação inoculado e não-inoculado (Figura 3); que apenas os genótipos 2, 4, 13, 27 e 30 apresentavam elevada produção e a mantiveram sob inoculação. O híbrido F1, genótipo 3, apesar de produtivo, foi altamente afetado pela inoculação, com expressiva redução na PG (Tabela 2). A PG foi drasticamente reduzida pela inoculação, média de $42 \%$, sendo que as linhagens parentais 1 e 2 , susceptível e resistente, apresentaram reduções de $94,78 \%$ e $21 \%$, respectivamente. Estudos diversos (Oliveira et al. 1998, 2002a e 2002b, Magalhães et al. 2001, Massola et al., 1999) têm demonstrado decréscimo diferencial na produção em plantas infectadas com espiroplasma, em função da cultivar, implicando reduções de até $64 \%$.

As características PROT, POD, PODesp, FA1, DFA1, FA2, DFA2, DFA/FA foram avaliadas no estádio de plântulas, imediatamente antes da inoculação, com o objetivo de se buscar um marcador bioquímico que pudesse estar correlacionado

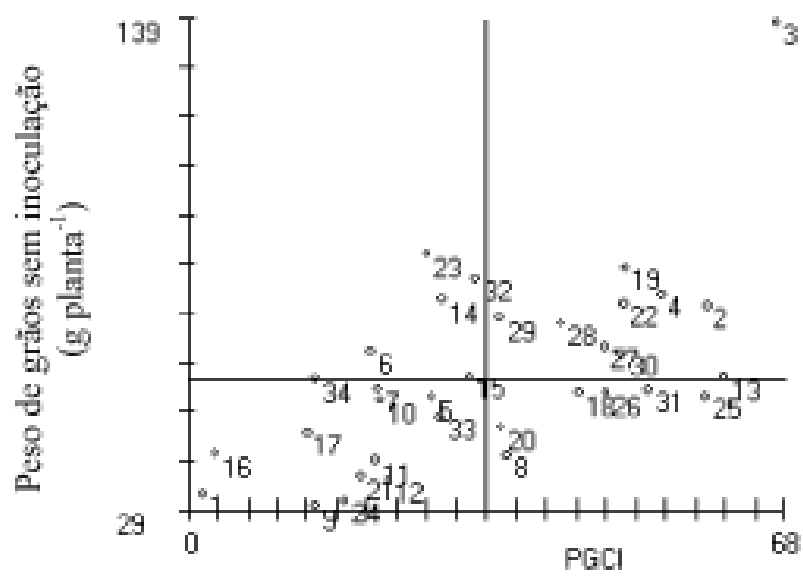

Peso de grãos sob inoculação (g planta ${ }^{-1}$ )

FIGURA 3. Distribuição dos genótipos para a característica produção de grãos, sob dois níveis de inoculação: inoculado e não-inoculado.

com a resistência. Desta forma, seria possível selecionar para resistência ao enfezamento pálido no estádio inicial de desenvolvimento, contribuindo em muito para programas de melhoramento. A severidade (SEV) do enfezamento pálido foi avaliada na época de produção das plantas. As características SEV, POD, PODesp, PROT e NE apresentaram diferenças significativas ao nível de $1 \%$ de probabilidade pelo teste F. Para o caracter DFA/FA, as diferenças foram detectadas ao nível de $5 \%$ de probabilidade e, para as características FA1, DFA1, FA2 e DFA2, não foi detectada diferença significativa.

Ao se realizar o teste de Scott-Knott, em nível de $5 \%$ de probabilidade, considerando a relação DFA/FA, todos os genótipos formaram um único grupo. Portanto, essa característica não foi eficiente para a detecção de genótipos resistentes. Por esse teste, a característica NE separou os genótipos de milho em dois grupos, sendo que a linhagem parental considerada resistente (P2), com nota 2,03, e o híbrido $\mathrm{F}_{1}$, com nota 1,92 ficaram em um mesmo grupo, diferente da linhagem parental susceptível (P1), com nota 1,13. Para SEV, foram também formados dois grupos, novamente $\mathrm{P} 2$ e P1 ficaram em grupos 
TABELA 2. Teste de Scott-Knott dos diferentes genótipos para a característica produção de grãos (PG), sob dois níveis de inoculação: inoculado e nãoinoculado.

\begin{tabular}{|c|c|c|}
\hline \multirow[b]{2}{*}{ Genótipos } & \multicolumn{2}{|c|}{$\frac{\text { Produção de Grãos }}{\left.\text { (g planta }^{-1}\right)}$} \\
\hline & Não-inoculado & Inoculado \\
\hline 9 & 30,07 a & 14,47 a \\
\hline 24 & $31,30 \mathrm{a}$ & 17,83 a \\
\hline 1 & $32,90 \mathrm{a}$ & $1,67 \mathrm{a}$ \\
\hline 12 & 36,07 a & 22,70 a \\
\hline 21 & $36,67 \mathrm{a}$ & 19,50 a \\
\hline 11 & $40,33 \mathrm{a}$ & $21,27 \mathrm{a}$ \\
\hline 8 & $41,47 \mathrm{a}$ & 36,33 a \\
\hline 16 & $41,83 \mathrm{a}$ & $3,10 a$ \\
\hline 17 & $46,47 \mathrm{a}$ & $13,57 \mathrm{a}$ \\
\hline 20 & $47,73 \mathrm{~b}$ & 35,57 a \\
\hline 33 & $50,10 \mathrm{~b}$ & 28,63 a \\
\hline 10 & $53,83 \mathrm{~b}$ & $21,80 \mathrm{a}$ \\
\hline 5 & $54,37 \mathrm{~b}$ & 24,60 a \\
\hline 25 & $54,67 \mathrm{~b}$ & $58,80 \mathrm{~b}$ \\
\hline 18 & $55,40 \mathrm{~b}$ & $44,37 \mathrm{~b}$ \\
\hline 26 & $55,50 \mathrm{~b}$ & $47,53 \mathrm{~b}$ \\
\hline 31 & $56,17 \mathrm{~b}$ & $52,23 \mathrm{~b}$ \\
\hline 7 & $56,30 \mathrm{~b}$ & 21,53 a \\
\hline 34 & $58,50 \mathrm{~b}$ & 14,46 a \\
\hline 13 & $58,97 \mathrm{~b}$ & $60,93 \mathrm{~b}$ \\
\hline 15 & $59,07 \mathrm{~b}$ & $32,00 \mathrm{a}$ \\
\hline 30 & $64,23 \mathrm{~b}$ & $49,33 \mathrm{~b}$ \\
\hline 6 & $64,73 \mathrm{~b}$ & $20,77 \mathrm{a}$ \\
\hline 27 & $65,80 \mathrm{~b}$ & $47,33 \mathrm{~b}$ \\
\hline 28 & $71,00 \mathrm{c}$ & $42,37 \mathrm{~b}$ \\
\hline 29 & $72,10 \mathrm{c}$ & $35,40 \mathrm{a}$ \\
\hline 2 & $74,87 \mathrm{c}$ & $59,03 \mathrm{~b}$ \\
\hline 22 & $75,40 \mathrm{c}$ & $49,50 \mathrm{~b}$ \\
\hline 14 & $76,07 \mathrm{c}$ & 28,93 a \\
\hline 4 & $77,37 \mathrm{c}$ & $53,73 \mathrm{~b}$ \\
\hline 32 & $80,93 \mathrm{c}$ & $32,70 \mathrm{a}$ \\
\hline 19 & $83,37 \mathrm{c}$ & $49,77 \mathrm{~b}$ \\
\hline 23 & $86,37 \mathrm{c}$ & $27,10 \mathrm{a}$ \\
\hline 3 & $138,07 \mathrm{~d}$ & $67,10 \mathrm{~b}$ \\
\hline
\end{tabular}

Valores seguidos pela mesma letra, na coluna, não diferem significativamente, a 5\% de probabilidade. distintos, respectivamente, com a menor $(1,2)$ e a maior $(4,4)$ nota, indicando que a avaliação da severidade dos sintomas do enfezamento pálido pode ser considerada efetiva como critério para a identificação de genótipos resistentes a essa doença. A efetividade da determinação da severidade da doença para discriminação entre genótipos resistentes e susceptíveis foi confirmada também pelos resultados obtidos através das avaliações de NE e PG. Aplicando-se o mesmo teste à característica $\mathrm{POD}$, o P1 apresentou o maior valor, sendo que P2 e F1 ficaram entre os genótipos com o menores valores. Esses dados diferem dos obtidos por Reuveni et al. (1992), em que maior atividade da peroxidase foi encontrada em plantas de melão resistentes a Pseudoperonospora cubensis. Para PODesp, os genótipos parentais tolerantes e suscetíveis foram agrupados em um mesmo grupo. Já para a característica PROT, esses genótipos ficaram em grupos distintos, com P1 apresentando a maior média. Entretanto, para essa característica, embora significativo o coeficiente de correlação genotípica e não significativo o de correlação fenotípica entre SEV e PROT (Tabela 3), os dados seguem a tendência dos obtidos por Ahmed et al. (1992), em que proteína total e solúvel em plantas de quiabo não inoculadas foram mais elevadas em variedades resistentes ao vírus do mosaico da nervura amarela.

As correlações entre valores fenotípicos e genotípicos das características que apresentaram significância na análise de variância encontram-se na Tabela 3. Pode-se observar que, em geral, as correlações foram de baixa magnitude, com exceção das correlações entre NExSEV (-0.838), SEVxPG $(-0.824)$ APxAE $(0,764)$ e NExPG (0.837). Para essas características, as correlações genotípicas apresentaram valores mais elevados; portanto, podese realizar seleção indireta para $\mathrm{PG}$, com base na SEV e NE, entretanto, não é possível selecionar para tolerância ao enfezamento pálido com base nas 
TABELA 3. Estimativas dos coeficientes de correlação fenotípica (acima da diagonal) e genotípica (abaixo da diagonal) entre severidade do enfezamento pálido e características bioquímicas e agronômicas.

\begin{tabular}{cccccccccc}
\hline Caracteres & DFA/FA & SEV & POD & PODesp & PROT & NE & AP & AE & PG \\
\hline DFA/FA & - & $-0,143$ & 0,245 & $-0,292$ & $0,344^{*}$ & 0,077 & 0,277 & 0,221 & $-0,058$ \\
SEV & $-0,263$ & - & $-0,001$ & 0,309 & $-0,239$ & $-0,838^{* *}$ & $-0,290$ & $-0,327$ & $-0,824^{* *}$ \\
POD & 0,115 & 0,109 & - & $-0,087$ & $0,584^{* *}$ & $-0,022$ & 0,329 & 0,078 & $-0,144$ \\
PODesp & $-0,391$ & 0,603 & $-0,007$ & - & $-0,728^{* *}$ & $-0,212$ & $-0,311$ & $-0,330^{*}$ & $-0,205$ \\
PROT & 0,322 & $-0,426$ & 0,717 & 0,700 & - & 0,123 & $0,443^{* *}$ & 0,288 & 0,057 \\
NE & $-0,189$ & $-0,943$ & $-0,033$ & $-0,338$ & 0,176 & - & 0,188 & 0,280 & $0,837^{* *}$ \\
AP & 0,334 & $-0,289$ & 0,386 & $-0,485$ & 0,579 & 0,132 & - & $0,764^{* *}$ & 0,297 \\
AE & 0,349 & $-0,389$ & 0,113 & $-0,475$ & 0,367 & 0,284 & 0,797 & - & $0,424^{*}$ \\
PG & $-0,356$ & $-0,978$ & $-0,252$ & $-0,007$ & $-0,063$ & 0,909 & 0,429 & 0,428 & - \\
\hline
\end{tabular}

* significativo a $5 \%$ de probabilidade, ${ }^{* *}$ significativo a $1 \%$ de probabilidade.

demais características avaliadas. Para as características SEV e PODesp, a correlação fenotípica de 0,309, embora não significativa, demonstra uma possível relação entre plântulas não-inoculadas e sua resistência ao espiroplasma, principalmente ao se considerar que a correlação genotípica de 0,603 foi significativa. Esse maior coeficiente de correlação genotípica, em relação ao correspondente coeficiente de correlação fenotípica, sugere que, apesar de uma forte associação entre os caracteres estudados, a correlação fenotípica foi reduzida devido à influência ambiental, uma vez que essa experimentação foi conduzida em campo. Singh et at. (1990) obtiveram, em Cyamopsis tetragonoloba, correlação negativa entre atividade da peroxidase e severidade da mancha bacteriana; entretanto, também verificaram influência ambiental sob o coeficiente de correlação fenotípica entre as características. Esses resultados sugerem que, possivelmente, a condução desse tipo de estudo em condições controladas de casa de vegetação, empregando-se um menor número de genótipos, possa apresentar um considerável aumento dessas correlações bioquímicas com a SEV.
Os zimogramas da peroxidase das plântulas não-inoculadas, de genótipos contrastantes quanto à resistência ao enfezamento pálido (dados não mostrados), não apresentaram-se exclusivas de determinado grupo, portanto, não permitindo com isto, associar isoforma(s) à resistência ou susceptibilidade.

\section{Conclusões}

A infecção por espiroplasma causou reduções significativas nas características altura das plantas (AP), altura de espiga (AE) e produção de grãos (PG).

Elevados valores de correlação entre severidade do enfezamento pálido (SEV), nota da espiga (NE) e produção de grãos (PG) mostram que essas características podem ser utilizadas como critério para seleção de genótipos resistentes ao enfezamento pálido.

Verificou-se tendência de as plantas resistentes ao enfezamento pálido apresentarem, no estádio de plântula, maiores valores de teor de proteínas solúveis (PROT) e menores valores de atividade específica da peroxidase (PODesp). 


\section{Agradecimentos}

Ao Dr. John Ralph, do Departamento de Floresta da Universidade de Wisconsin-Madison, EUA, a gentileza em nos fornecer o padrão do ácido 5,5`-di-ferúlico.

A Célio Ramos das Neves, auxiliar de operações I, da Embrapa Milho e Sorgo, a participação na condução dos experimentos de campo e laboratório.

\section{Literatura Citada}

ALBUQUERQUE, P.E.P.; ANDRADE, C.DE L.T. de. Uso de planilha eletrônica para a programação da irrigação na cultura do milho. Sete Lagoas: Embrapa Milho e Sorgo, 2000. 24p. (Embrapa Milho e Sorgo. Circular Técnica, 5).

AHMED, N.; THAKUR, M. R.; BAJAJ, K. L.; CHEEMA S. S. Biochemical basis of resistance to yellow vein mosaic virus in okra. Plant Disease Reserach, Ludhiana, v. 9, p. 20-25, 1992.

BARROS, T. S. L.; DAVIS, R. E.; RESENDE, R. O.; DALLY E. L. Design of a polymerase chain reaction for specific detection of corn stunt spiroplasma. Plant Disease, St. Paul, v. 85, p. 475480, 2001.

BAR-ZUR, Y.; TADMOR, J.A.; SHIMONI, M.; REUVENI, R. Resistance to northern leaf blight in maize (Zea mays) conditioned by the HtN gene and the association with isoperoxidases. Canadian Journal of Plant Pathology, Ottawa, v. 20, p. 2834, 1998.

BEDENDO, I. Enfezamento vermelho e enfezamento pálido do milho associados a fitoplasma e espiroplasma: sintomatologia, etiologia e técnicas para detecção e identificação destes agentes. Summa Phytopathologica, Piracicaba, v. 3, p. 190-196, 1999.

BRADFORD, M. M. A rapid and sensitive method for the quantitation of microgram quantities of protein utilizing the principle of protein-dye binding. Analytical Biochemistry, New York, v. 72, p. 255256, 1976.

CRUZ, C.D. Programa Genes: versão Windows; aplicativo computacional em genética e estatística, Viçosa: UFV, 2001. 648 p.

HAYAT, M. A. Principles and Techniques of Electron Microscopy: biological applications. Boca Raton: CRC Press. 1989. 469 p.

KITAJIMA, E. W.; COSTA A. S. Micoplasma: possível agente etiólogico de certas moléstias de plantas. Ciência e Cultura. São Paulo, v. 22, p. 351363, 1970.

LEE, I. M.; BERTACCINI, A.; VIBIO, M.; GUNDERSEN, D. E. Detection of multiple phytoplasmas in perennial fruit trees with decline symptoms in Italy. Phytopathology, St. Paul, v. 85, p. 728-735, 1995.

MAGALHÃES, P. C.; OLIVEIRA, E.; GOMIDE, R. L.; VASCONCELOS, C. \& SOUZA I. R. P. Aspectos fisiológicos de plantas de milho infectadas por molicutes sob diferentes níveis de água no solo. Revista Brasileira de Fisiologia Vegetal, Londrina, v. 13, p. 293-301, 2001.

MASSOLA JUNIOR, N.S.; BEDENDO, I.P.; AMORIM, L. \& LOPES, J.R.S. Quantificação de danos causados pelo enfezamento vermelho e enfezamento pálido do milho em condições de campo. Fitopatologia Brasileira, v. 24, p. 136-142, 1999.

NAULT, L. R. Maize bushy and corn stunt: a comparison of disease symptoms, pathogen host ranges, and vectors. Phytopathology, St. Paul, v. 7, p. 659-662, 1980.

OLIVEIRA, C. M. Variação morfológica entre populações de Dalbulus maidis (DeLong \& Wolcott, 1923) (Hemiptera: Cicadellidae) de 
algumas localidades do Brasil. 1996. 69f. Dissertação (Mestrado) - Escola Superior de Agricultura Luiz de Queiroz, Universidade São Paulo, Piracicaba.

OLIVEIRA, E.; OLIVEIRA, C. M.; SOUZA, I. R. P.; MAGALHÃES, P.C.; CRUZ, I. Enfezamentos em milho: expressão de sintomas foliares, detecção dos molicutes e interações com genótipos. Revista Brasileira de Milho e Sorgo, Sete Lagoas, v. 1, n. 1, p. 53-62, 2002.

OLIVEIRA, E.; WAQUIL, J. M.; FERNANDES, F. T.; PAIVA, E.; RESENDE, R. O.; KITAJIMA E. W. Enfezamento pálido e enfezamento vermelho na cultura do milho no Brasil Central. Fitopatologia Brasileira, Brasília, v. 23, p. 45-47, 1998.

OLIVEIRA, E.; OLIVEIRA, C. M.; SOUZA, I. R. P.; MAGALHÃES, P. C.; CRUZ I. Molicutes e vírus em milho na safrinha e na safra de verão. Revista Brasileira de Milho e Sorgo, Sete Lagoas, v. 1, n. 2, p. 38-46, 2002a.

OLIVEIRA, E.; MAGALHÃES, P. C.; GOMIDE, R. L.; VASCONCELOS, C. A.; SOUZA, I. R. P.; OLIVEIRA, C. M.; CRUZ, I.; SCHAFFERT, R. E. Growth and nutrition of mollicute-infected maize. Plant Disease, St. Paul, v. 86, p. 945-949, 2002 b.

PRATES, H.T.; SOUZA I.R.P., PIRES, N.M.; LOPES, M.J.C.; NAVES, F.O.; TEIXEIRA, C. Quantificação dos ácidos ferúlico e 5,5'-diferúlico de parede celular de milho. In: CONGRESSO NACIONAL DE MILHO E SORGO, 24., 2002, Florianópolis - Meio ambiente e a nova agenda para o agronegócio de Milho e Sorgo - [resumos expandidos]. Sete Lagoas: ABMS/Embrapa Milho e Sorgo/EPAGRI, 2002. CD Rom.

REUVENI, R.; SHIMONI, M.; KARCHI, Z.; KUÉ, J. Peroxidase activity as a biochemical marker of resistance of muskmelon (Cucumis melo) to
Pseudoperonospora cubensis. Phytopathology, St. Paul, v.7, p.749-753, 1992.

SAGHAI-MAROOF, M.A; SOLIMAN, K.M.; JORGENSEN, R.A.; ALLARD, R. W. Ribosomal DNA spacer length polymorphisms in barley: Mendelian inheritance, chromosomal location, and population dynamics. Proceedings of the National Academy of Sciences, Washington, v. 81, p. 80148019. 1984.

SCOTT, A. J.; KNOTT, M. A. A cluster analysis method for grouping means in the analysis of variance. Biometrics, Raleigh, v. 30, n.3, p5 07-512, 1974.

SHIMONI, M.; BAR-ZUR, A.; REUVENI. The relationship between isozymes of and resistance of near-isogenic maize inbred lines to Exserohilum turcicum. Canadiar Journal of Plant Pathology, Ottawa, v. 18, p. 403-408, 1996.

SINGH, J. V.; SAINI, M. L.; ARORA, S. K.; SINGH, A. P.; GANDHI, S. K. Relationship between bacterial blight severity and biochemical parameters in clusterbean (Cyamopsis tetragonoloba). Annals of Biology, Ludhiana, v. 6, p. 117-121, 1990.

SOUZA, I.R.P.; MACADAM, J.W. A transient increase in apoplastic peroxidase activity precedes decrease in elongation rate of $\mathrm{B} 73$ maize (Zea mays L.) leaf blades. Physiologia Plantarum, Copenhagen, v. 104, p. 556-562, 1998.

SOUZA, I.R.P.; PRATES, H.T.; LOPES, M.J.C.; PIRES, N.M.; NAVES, F.O.; TEIXEIRA, C. Ajuste de metodologias de extração de parede celular e de liberação de ácidos fenólicos para quantificação por HPLC. In: CONGRESSO NACIONAL DE MILHO E SORGO, 24., 2002, Florianópolis - Meio ambiente e a nova agenda para o agronegócio de Milho e Sorgo - [resumos expandidos]. Sete Lagoas:ABMS/Embrapa Milho e Sorgo/EPAGRI, 2002. CD Rom. 